\title{
Evaluation of measurement uncertainty of profile parameters using a Monte Carlo method
}

\author{
Szacowanie niepewności pomiaru parametrów profilu metodą Monte Carlo
}

\author{
STANISŁAW ADAMCZAK \\ JACEK ŚWIDERSKI \\ TOMASZ DOBROWOLSKI \\ THOMAS G. MATHIA *
}

\begin{abstract}
The advantages of the Monte Carlo method for estimating the uncertainty of measurement of the amplitude parameters of the primary profile determined during the measurements of the surface texture are presented.

KEYWORDS: measurement uncertainty, Monte Carlo method, surface texture
\end{abstract}

Parameters describing the surface condition were introduced to allow comparison of the unevenness of different surfaces and to verify the fulfillment of specific requirements. With regard to the two-dimensional analysis, they are determined for various components of the inequality profile: the primary profile $(P)$, the waviness profile $(W)$ and the roughness profile $(R)$.

The uncertainty is an indispensable element of the measurement result, which allows for adjudication of compliance with the specification or for confirming scientific hypotheses.

The basic algorithms for estimating standard uncertainties and extended uncertainties for a given confidence level are based on the recommendations announced by the ISO International Organization for Standardization in the guide: Guide to the expression of uncertainty in measurement (GUM 1995 - Polish translation of the guide issued by the Central Office of Measures in 1999) [1]

The guide allows uncertainty estimation using methods $A$ and $B$. In the method type A the measurement uncertainty is determined based on statistical analysis of a series of repeat observations, if the spread of measured values is greater than the resolution of the measuring instrument. It is assumed that the observation results represent the values

\footnotetext{
* Prof. dr hab. inż. Stanisław Adamczak (adamczak@tu.kielce.pl), mgr inż. Jacek Świderski (swiderski@tu.kielce.pl), mgr inż. Tomasz Dobrowolski (t.dobrowolski@tu.kielce.pl) - Wydział Mechatroniki Budowy Maszyn Politechniki Świętokrzyskiej; dr hab. inż. Thomas G. Mathia (thomas.mathia@ec-lyon.fr) - Centre National de la Recherche Scientifique (CNRS), Laboratoire de Tribologie et Dynamique des Systemes (LTDS), Ecole Centrale de Lyon, France
}

of the random variable. To determine the uncertainty component by the type A method, results from measurements performed under repeatability conditions are needed. The B method is used in all other cases where it is not possible or the statistical analysis of the observation results is not justified.

Supplement 1 to the "Guide to the expression of uncertainty in measurement": JCGM 101: 2008 contains the necessary information on estimating uncertainty of measurement using the Monte Carlo (MC) method, based on propagation of input quantities [2]. The principle applies when the measurement model contains any number of input

quantities and a single output quantity, understood as the measured quantity. The Monte Carlo method is an alternative to the classical way of calculating the uncertainty of measurement resulting from the law of its propagation, especially when the linearization of the measurement model is unjustified and the distribution related to the initial size is asymmetrical.

The Monte Carlo method is based on the principle of propagation of probability distributions realized through a developed mathematical model of measurement using Monte Carlo simulation. The measure of the measurement result is the probability distribution related to the output quantity, determined on the basis of the distributions of the input quantities. The measurement result is presented in the form of the parameters of this distribution: expected value, standard deviation and distribution quantiles for a given probability, as the limits of the extension interval. The measured quantity is characterized by the probability density function. Its expected value is treated as the best estimate of the measured value, and the standard deviation - as the standard uncertainty associated with this estimate. This method can be used when, due to the complexity of the measurement model [3-5], the conditions necessary to apply the law of propagation of uncertainty are not met.

The mathematical model of scalar input size measurement can be expressed by means of:

$$
Y=f(\boldsymbol{X})
$$


where: $Y$ - initial size; $\boldsymbol{X}$ - input quantity represented by $N$ input quantities $\left(X_{1}, \ldots, X_{N}\right) T$.

Each of the input quantities $X_{i}$ is a random variable with possible values of $\xi_{i}$ and the expected value of $x_{i}$. The output $Y$ is a random variable with possible values of $\eta$ and the expected value of $y$.

Fig. 1 presents the essence of uncertainty estimation according to GUM, based on the principle of propagation of uncertainty, and in fig. 2 - using MC simulation, based on the principle of propagation of distributions.

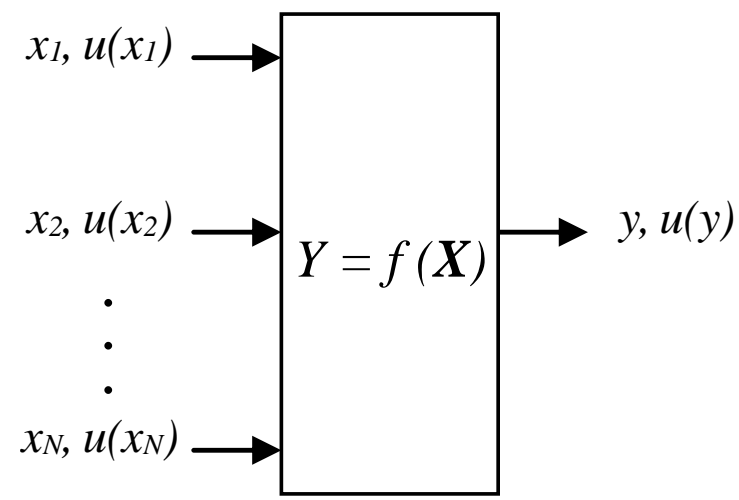

Fig.1. Essence of estimating uncertainty according to GUM

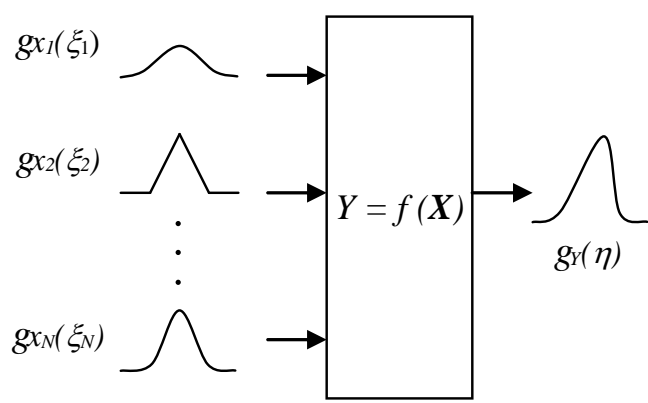

Fig. 2. Essence of estimating uncertainty according to MC

\section{Analyzed profile}

In order to present the possibilities of using the MC method to estimate the uncertainty of profile parameters measurement, a random primary profile consisting of 2000 points was used (fig. 3).

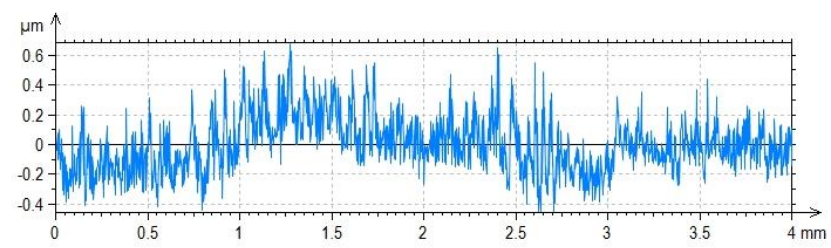

Fig. 3. Measured primary profile

The Monte Carlo method uses the following steps:

- determining the input quantities, on which the output value of the measurement depends

- defining the output size,

- development of a mathematical model defining the relationship between the input quantities and the output size of the measurement,

- assumption of probability distributions for input quantities,

- determination of the probability density function of the output quantity by the adopted mathematical model, based on the distributions of the input quantities using Monte Carlo simulation,
- determination on the basis of the output value distribution: the expected value, which is the estimate of the initial value, the standard deviation as the standard uncertainty associated with this estimate and the distribution quantiles for a given probability.

The input quantities in the adopted measurement model are the coordinates $z$ of the original profile shown. The output value is the value of a specific amplitude parameter.

The following parameters of the primary profile were analyzed:

- height of the highest elevation of the profile $P_{\mathrm{p}}$ according to the formula:

$$
P p=\max \left\{z_{1}, \ldots, z_{n}\right\}
$$

- depth of the lowest $P_{\mathrm{v}}$ profile recess according to the formula:

$$
P v=\left|\min \left\{z_{1}, \ldots, z_{n}\right\}\right|
$$

- arithmetic mean of the ordinates of the $P_{\mathrm{a}}$ profile, determined from the formula:

$$
P a=\frac{1}{n} \sum_{i=1}^{n}\left|z_{\mathrm{i}}\right|
$$

- the root mean square of the profile $P_{\mathrm{q}}$, determined from the formula:

$$
P q=\sqrt{\frac{1}{n} \sum_{i=1}^{n} \mathrm{z}_{\mathrm{i}}^{2}}
$$

- $P_{\text {sk }}$ asymmetry coefficient determined from the formula:

$$
P s k=\frac{1}{(P q)^{3}} \cdot \frac{1}{n} \sum_{i=1}^{n} \mathrm{z}_{\mathrm{i}}^{3}
$$

- the slope ratio of the $P_{\mathrm{ku}}$ profile determined from the formula:

$$
P k u=\frac{1}{(P q)^{4}} \cdot \frac{1}{n} \sum_{i=1}^{n} \mathrm{z}_{\mathrm{i}}^{4}
$$

where: $n$ - number of points, $z$ - ordinates of the $i$-th point.

Each of the presented dependencies, defining the profile parameter, is also a mathematical model describing the relations between the input quantities and the output size of the measurement.

The result of measurement of individual coordinates of the profile is burdened with errors resulting from $[6,7]$ :

- measuring noise, which consists of vibrations in the mechanical profile of the profilometer and vibrations in the place of installation of the device, which were not suppressed by the instrument's vibration isolation system,

- linearity error of the instrument's measuring sensor,

- error in the straightness of the reference profile reference profile,

- elastic deformation of the material of the measured element under the effect of the imaging blade,

- sampling error in the $X$ axis, 
- the effect of mechanical inequalities filtering through the top of the imaging blade,

- errors related to measuring tip kinematics, consisting in the possibility of contact loss of the cutting edge with the measured surface.

In order to investigate the impact of the assumed probability distribution of input quantities on the function of the probability density of the output size for individual profile parameters, two types of probability distributions were assumed for the input quantities:

- uniform distribution (rectangular) with an expected value equal to the $z$-coordinate of the $i$-th point and a range of variability of $\pm 0.03 \mu \mathrm{m}$,

- Gaussian normal distribution with an expected value equal to the $z$-coordinate of the $i$-th point and a standard deviation of $0.01 \mu \mathrm{m}$.

The assumed parameters of both probability distributions provide the same range of variations in input quantities.

For these cases, a Monte Carlo simulation was carried out by performing 1000 times the sampling of a set of input quantities.

\section{Analysis of results}

The specification of the values of the profile parameters, calculated on the basis of its measured coordinates and the MC simulation for the distribution of normal and uniform probability density function of the input quantities, is given in tab. I.

\section{TABLE I. Values of profile parameters}

\begin{tabular}{|l|l|l|l|l|l|l|}
\hline \multirow{2}{*}{$\begin{array}{c}\text { Method of } \\
\text { determination }\end{array}$} & $\begin{array}{l}\mathrm{Pq} \\
\mu \mathrm{m}\end{array}$ & $\begin{array}{l}P p \\
\mu \mathrm{m}\end{array}$ & $\begin{array}{l}P V \\
\mu \mathrm{m}\end{array}$ & $P k u$ & $P s k$ & $\begin{array}{c}P a \\
\mu \mathrm{m}\end{array}$ \\
\hline $\begin{array}{l}\text { Calculated } \\
\text { from the } \\
\text { profile }\end{array}$ & 0,1903 & 0,685 & 0,458 & 3,298 & 0,514 & 0,1497 \\
\hline $\begin{array}{l}\text { MC simulation } \\
\text { (normal } \\
\text { distribution) }\end{array}$ & 0,1906 & 0,689 & 0,464 & 3,296 & 0,512 & 0,1499 \\
\hline $\begin{array}{l}\text { MC simulation } \\
\text { (rectangular } \\
\text { distribution) }\end{array}$ & 0,1911 & 0,696 & 0,472 & 3,292 & 0,508 & 0,1503 \\
\hline
\end{tabular}

Tab. II presents the uncertainty estimated for the assumed distributions of the density function of the input quantities estimated by the MC method.

\section{TABLE II. Uncertainty of measuring profile parameters}

\begin{tabular}{|c|c|c|c|c|c|c|}
\hline \multirow{2}{*}{$\begin{array}{l}\text { Method of } \\
\text { determination }\end{array}$} & \multicolumn{6}{|c|}{ Measurement uncertainty } \\
\hline & $\begin{array}{l}P q \\
\mathrm{~nm}\end{array}$ & $\begin{array}{l}P p \\
\mathrm{~nm}\end{array}$ & $\begin{array}{l}P V \\
\mathrm{~nm}\end{array}$ & $P k u$ & Psk & $\begin{array}{l}\mathrm{Pa} \\
\mathrm{nm}\end{array}$ \\
\hline $\begin{array}{l}\text { MC simulation } \\
\text { (normal } \\
\text { distribution) }\end{array}$ & 0,4 & 15 & 15 & 0,03 & 0,01 & 0,4 \\
\hline $\begin{array}{l}\text { MC simulation } \\
\text { (rectangular } \\
\text { distribution) }\end{array}$ & 0,4 & 11 & 11 & 0,04 & 0,02 & 0,4 \\
\hline
\end{tabular}

Examples of probability density functions for output quantities $P_{\mathrm{q}}$ and $P_{\mathrm{p}}$ obtained for both assumed probability distributions of input quantities are shown in fig. 4 and fig. 5 .
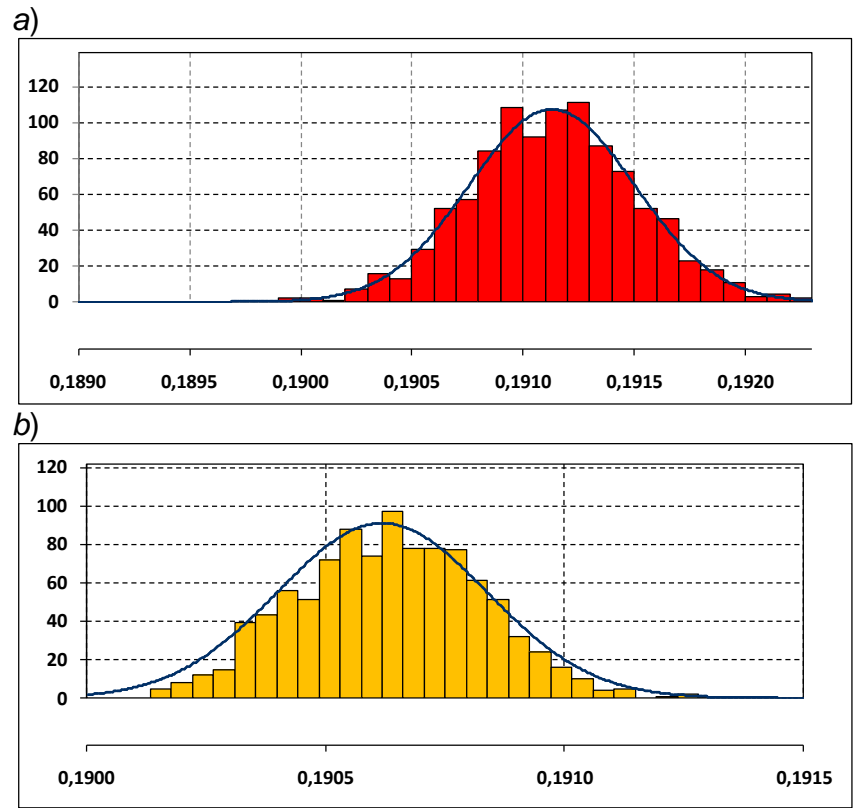

Fig. 4. Functions of probability density of $P_{\mathrm{a}}$ parameter: a) for uniform distribution of input quantities, b) for distribution of normal input quantities
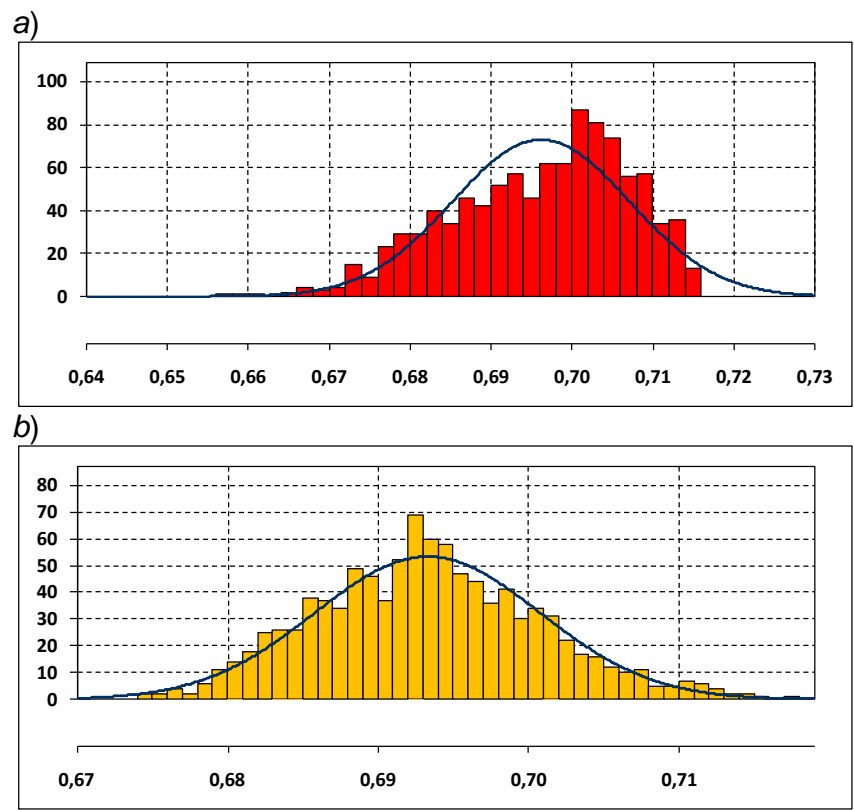

Fig. 5. Functions of probability density of parameter $P_{\mathrm{p}}$ : a) for uniform distribution of input quantities, b) for distribution of normal input values

\section{Conclusions}

The use of the Monte Carlo method allows to avoid complicated calculations of partial derivatives. In addition, the method makes it possible to specify the estimate of the initial value for non-linear measurement equations and the standard uncertainty associated with this estimate. It is possible to determine the range of coverage, corresponding to a given confidence level, when the density function of the output size cannot be approximated by the Gaussian or Student $t$-distribution - which takes place with the dominant component of the non-Gaussian distribution or non-linear measurement model.

For the assumed rectangular probability distribution of the input quantities, the probability density functions of the output quantities have the character of a normal distribution, with the exception of the distribution for the $P_{\mathrm{p}}$ and $P_{\mathrm{v}}$ parameters. 
Publication based on the results obtained as part of the PBS2 project funded by NCBR (No. PBS2/A6/20/2013) "Research and assessment of reliability of modern methods of measuring surface topography in the micro and nano scale".

\section{REFERENCES}

1. JCGM 100:2008 Evaluation of measurement data. Guide to the expression of uncertainty in measurement.

2. JCGM 101:2008 Evaluation of measurement data. Suplement 1 to the "Guide to the expression of uncertainty in measurement": Propagation of distributions using a Monte Carlo method.

3. PN-ISO 3534-1:2009 Statystyka. Słownik i symbole. Część 1: Ogólne terminy statystyczne $\mathrm{i}$ terminy wykorzystywane $\mathrm{w}$ rachunku prawdopodobieństwa.

4. Fotowicz P. „Nowe podejście w dziedzinie wyrażania niepewności pomiaru”. Pomiary Automatyka Robotyka. 7-8 (2006): pp. 34-37.

5. Płowucha W., Jakubiec W., Rosner P. „Szacowanie niepewności pomiaru - metoda Monte Carlo”. Mechanik. 12 (2017): pp. $1152-1154$.

6. Wieczorowski M., Gapiński B., Grochalski K., Miller T. „Teoretyczne aspekty analizy wybranych źródeł błędów w profilowych pomiarach nierówności powierzchni”. Mechanik. 4 (2017): pp. 335-338.

7. Adamczak S., Świderski J., Dobrowolski T. „Wybrane zagadnienia stykowych pomiarów struktury geometrycznej powierzchni”. Mechanik. 4 (2017): pp. 328-331.

Translation of scientific articles, their computer composition and publishing them on the website www.mechanik.media.pl by original articles in Polish is a task financed from the funds of the Ministry of Science and Higher Education designated for dissemination of science.

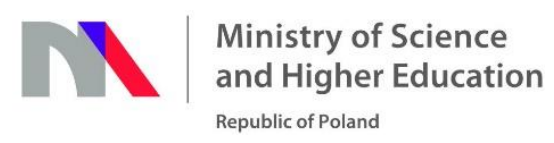

